\title{
P.Oxy. IV 824: An Aberrant Date Clause of Ptolemy X
}

\author{
Nikolaos Gonis*
}

\begin{abstract}
Revised edition of an Oxyrhynchus papyrus that appears to be the sole testimony to a regnal date clause of Ptolemy $\mathrm{X}$ Philometor which omits his name 'Alexandros'.
\end{abstract}

Keywords: Oxyrhynchus, Ptolemy X Philometor

DOI 10.1515/apf-2016-0008

This papyrus was briefly described in P.Oxy. IV, p. 258: ' 4.8 x $2.5 \mathrm{~cm}$. Fragment containing parts of the first 10 lines of a contract dated in the sole reign of Ptolemy (Alexander the god) Philometor (B.C. 101-88).' It was first published in full in L. Fay Kaufman, 'Two Papyri at Wellesley College', BASP 3 (1965-1966) 29, from an undergraduate dissertation; it was not reprinted in SB, but was included in DDbDP. The text can be improved upon in numerous places; a new edition is presented below.

The interest of this scrap lies in the fact that the regnal date clause does not seem to mention the second name of Ptolemy X Philometor, viz. 'Alexandros'. This appears to be unique, but is probably an inadvertent omission. The lack of a reference to a co-regent is also noteworthy. The month date, Pachon 19 (1. 5) indicates that the text does not come from the short time between the death of Cleopatra III and the accession of Bere-

Vorbemerkung: I am grateful to Mariana S. Oller, Associate Curator of Special Collections, Wellesley College, for supplying a digital image and granting permission to reproduce it. My thanks are also due to Gabriella Messeri for reading a draft. All dates are 'BC'.

"Kontakt: Nikolaos Gonis, Department of Greek and Latin, University College London, London WC1E 6BT, United Kingdom, <n.gonis@ucl.ac.uk> 
nice III in October 101. ${ }^{1}$ There are several Demotic documents from later years that make no reference to Berenice: she appears only sporadically in years $17(=98 / 97)$ and $18(97 / 96)$, and is not mentioned at all in years 19 (96/95) and 20 and (95/94). ${ }^{2}$ The same picture emerges from Greek inscriptions. Berenice resurfaces in Demotic texts in year 21, but not in Greek papyri, at least not with this name. The last reference to Berenice in a Greek papyrus dates from Mecheir 4, year 17 = 17 February 97 (P.Lond. III 1208). No dating clauses of Ptolemy $X$ have survived from almost five years after that; when our record resumes, there is no mention of Berenice (P.Tebt. I 109 [22 Dec. 93], 104 [22 Feb. 92]). Another period of silence in our documentation follows, until we find Ptolemy again in P.Lond. III 1209 of Epeiph 23, year $25=2$ August 89, but this time he appears alongside queen Cleopatra, another name of Berenice (the name 'Cleopatra' occurs in Demotic documents from 91/90 onwards). P.Oxy. 824 may date from between 97 and 89 , years 17 to 25 .

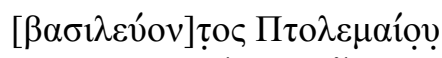

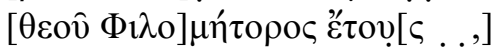

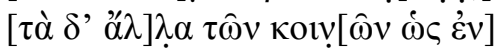

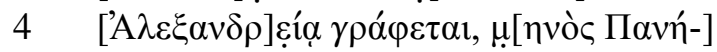

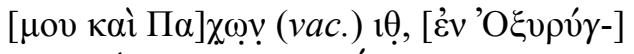

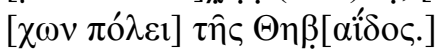

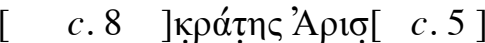

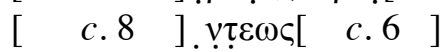

[ $c .8$ ] $\alpha \propto \grave{~} \Theta \alpha \tau \rho \hat{\eta} \tau\left[\begin{array}{ll}1 & c .6\end{array}\right]$

[ c.10]........[

'In the reign of Ptolemy, god Philometor, year $n$, and the rest of the customary formulas as written in Alexandria, in the month of Panemos and Pachon 19, in the city of the Oxyrhynchi of the Thebaid. -krates son of Aris - ... (verb) (to) ... and (to) Thatres ...'

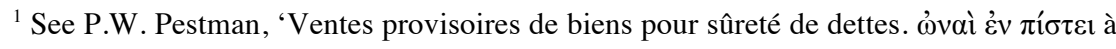
Pathyris et à Krokodilopolis', in Textes et études de papyrologie grecque, démotique et copte (P.L. Bat. 23, 1985) 52 n. 17, 53 n. 20.

${ }^{2}$ See Pestman, Chronologie égyptienne d'après les textes démotiques: 332 av. J.-C.453 ap. J.-C. (P.L. Bat. 15, 1967) 72 n.c.
} 
The papyrus appears to be complete at the top, though very little of the upper margin is extant.

$1 \beta \alpha \sigma \lambda \lambda \dot{\varepsilon}] \omega \varsigma$ is not a possible reading. i.e., this cannot be a dating clause of Cleopatra III and Ptolemy X Alexander I Philometor. There is no room

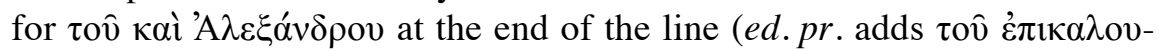

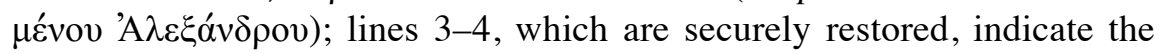
length of the break.

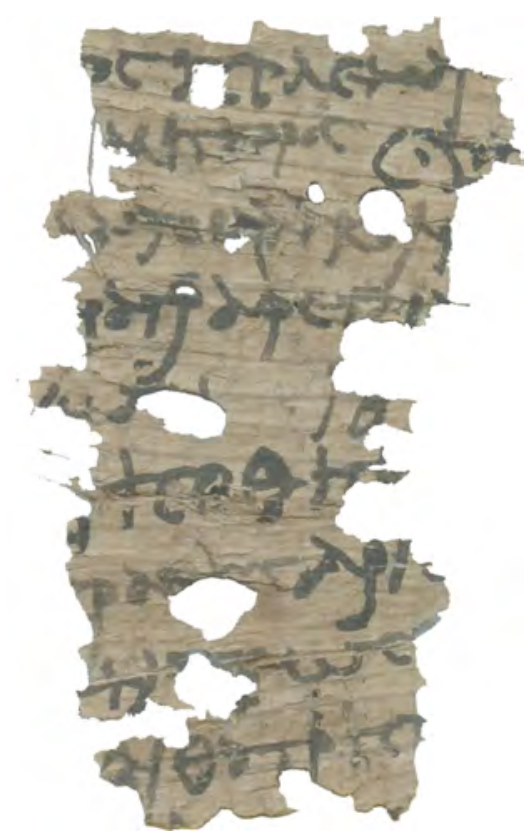

2 हैं range of options see above, introd.

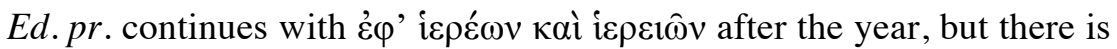
no reference to eponymous priests in contemporary documents from Oxyrhynchus; see M. Minas, 'Kein eponymer Priester. Zu P.Oxy. XIV 1723 descr.', APF 42 (1996) 140.

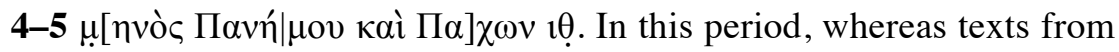
other nomes give the day of the month after both the Macedonian and the Egyptian months, Oxyrhynchite documents link the months with кaí and 
refer to the day only once. Contrast e.g. P.Oxy. XLIX 3482.2 (73 B.C.)

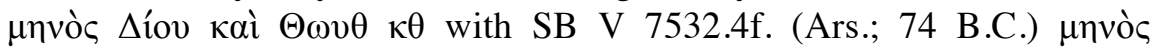

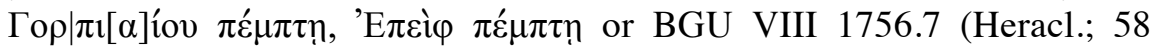

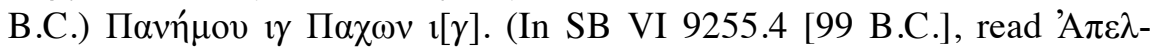

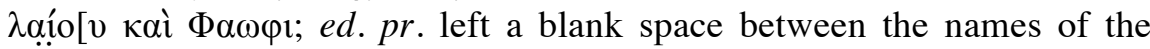

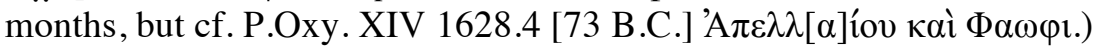

In the period under consideration, Pachon 19 corresponds to 3 June 100-98, 2 June 97-94, 1 June 93-90, 30 May 89 B.C.

7 The break at the start of the line took away a verb such as $\varepsilon \delta \alpha ́ v \varepsilon ı \sigma \varepsilon v$, $\dot{\varepsilon} \mu i ́ \sigma \theta \omega \sigma \varepsilon v, \dot{o} \mu \mathrm{o} \alpha \sigma \varepsilon \varepsilon \hat{\imath}$, etc. The beginning of the verb might have stood at the end of 1.6 .

] ূ̣ótnc. Not much will have been lost from the beginning of the name;

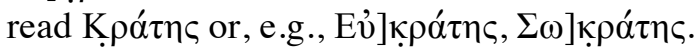

8 ]. $v \tau \varepsilon \omega \varsigma$ is no doubt the end of a name in the genitive. It could be the

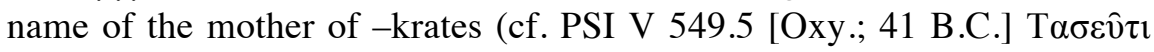

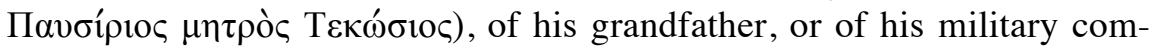

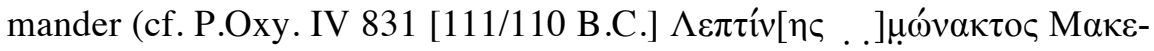
$\delta \omega ̀ v \tau \hat{\omega} v \Sigma \omega \gamma \gamma \imath$ á́ploc $\pi \varepsilon \zeta \hat{\omega} v)$. 